\title{
Interruption of journal flow
}

At last, there is now fairly accurate information about the so-called FDA Embargo incident. Actually, the Food and Drug Administration (FDA) has no involvement in the decision to keep the supplements of the British Journal of Dermatology, volume 127, supplement 41 (1992), and the Seminars in Oncology, volume 19 , supplements $1,2,5$, and 6 (1992), from being distributed in the United States. The pharmaceutical firms and the publishers responsible for these supplements misunderstood the FDA regulations as they involve institutions and libraries. The situation has been rectified, and U.S. medical libraries will receive the journal supplements.

I wish to thank all the health sciences librarians, MLA headquarters, MLA committees, and senior staff of the National Library of Medicine for their assistance. After numerous telephone conversations, discussions, and facsimile and e-mail transmissions, Addeane S. Caelleigh, editor of Academic Medicine, and I have sorted the events leading to this unfortunate incident. Her enlightening editorial in Academic Medicine covers the complexities involved in this case and reminds all of us who cherish the principles of the Bill of Rights that we must guard and protect our freedoms, especially as they pertain to speech and the press [1].

\section{Naomi C. Broering \\ Editor}

\section{Reference}

1. Caelleigh AS. Journal supplements, libraries, and the FDA. Acad Med 1992 Dec;64:838-9.

\section{Journal supplements, libraries, and the FDA}

Controversy over commercial support for scholarly and educational activities in medicine usually arises over two issues: support for educational activities and support for science publishing. Drug companies' support of continuing medical education troubles the academic medicine community, and several groups have issued policies or guidelines that try to balance the benefits of the financial support with the obligations to separate support from control of content and to acknowledge the support appropriately [1-3].

Pharmaceutical companies' financial support for publishing journal supplements, usually symposium proceedings, also raises concerns. A recent study showed that such commercial support has led to a large increase in the number and proportion of symposium proceedings sponsored by drug companies and that they often have promotional attributes and are not peer reviewed. The authors recommend general guidelines for all parties involved in publishing these supplements [4].

$A$ related issue has not yet been addressed: the confusion about restrictions on these supplements. This confusion leads medical faculty members, medical librarians, journal publishers, and drug companies into tangles such as the recent situation involving the British Journal of Dermatology (BJD). The first alarm was raised over censorship, but the story turns out to be not about censorship but about lack of clear guidelines and virtually no communication among all the parties involved.

Although unconscious biases and informal censorship are as rife among academics, scientists, and librarians as elsewhere, the merest hint of formal censorship will send these diverse groups flying to defend a right that is at the heart of all their enterprises - the right to free flow of information. Small wonder that the alarm was raised when, in October, a government agency appeared to be interfering with the dissemination of a research publication.

What gave rise to this agitation among the ranks? A notice that the publisher of the British Journal of Dermatology sent its U.S. subscribers:

Supplement 41 (1992), title: "Photodamage in the Community and the Place of Long-Term Topical Retinoid Therapy"

The publishers regretfully inform all U.S. subscribers that, in accordance with current FDA guidelines on the distribution within the U.S. of literature covering the use of drugs for unlicensed indications, the U.S. circulation of British Journal of Dermatology Vol. 127, Supplement 41 (1992) has been withheld.

Within the U.S., Retin-A is currently licensed for use in treating acne. It has also now been submitted to the FDA [Food and Drug Administration] for the granting of a license for treating photodamaged skin. The granting license is currently pending. When granted, copies of the supplement will be released in the U.S. 
In worried exchanges, faculty and librarians deplored the "FDA embargo" and "government censorship." Those who knew the mandate and workings of the FDA realized that it does not have the authority either to prevent a British publisher from mailing a periodical to its U.S. subscribers or to forbid the U.S. Postal Service to deliver it. Nonetheless, the publisher's statement was read as evidence of FDA involvement in the withholding of a supplement to an influential medical journal.

Did the FDA embargo this supplement? Contrary to popular assumption, the answer is no, according to discussions with the FDA and the publisher. Yet questions raised by the circumstances may be as important to the academic medical community as the question of censorship.

The picture of what happened was pieced together from discussions with medical librarians; FDA officials; editors at Blackwell Publishers, which publishes the British Journal of Dermatology; and officials at Ortho Pharmaceuticals, which makes tretinoin (Retin-A), the focus of the withheld supplement. Naomi Broering, director of the medical center library at Georgetown University and editor of the Bulletin of the Medical Library Association, worked to collect information from the library community.

This picture shows not an imposition of censorship but rather a clash of two "goods": first, drug advertising should be regulated; second, legitimate scientific information should flow unimpeded through the academic and research communities.

In the case of the $B J D$ supplement, endeavors to promote these two wholly appropriate ends collided - and the academic and medical communities were unprepared to handle the resulting imbroglio.

What happened to the BJD supplement? The FDA is charged with regulating drug advertising. To do so, it sets advertising guidelines, and, because pharmaceutical firms often support symposia and the journal supplements that grow from them, these guidelines sometimes apply to such supplements. Johnson \& Johnson is the parent company of Ortho Pharmaceuticals; the international arm of Johnson \& Johnson is Cilog, which underwrote a British conference on the use of Retin-A to treat photodamaged skin as well as the supplement that carried the symposium papers. This use of Retin-A is not licensed in the United States but is under consideration for approval by the FDA.

The difficulty arose when the supplement-wholly proper in Britain-was ready for distribution before the new use was approved by the FDA. The U.S. company realized that it would violate FDA guidelines if it (in this case, its international parent, Cilog) advertised an unlicensed use through a supplement distributed in the United States. Therefore, Johnson \& Johnson asked Cilog to ask Blackwell Publishers to withhold the supplement from U.S. subscribers until the FDA approval hearings were completed and the new use, presumably, was approved. Understanding the strictness of the FDA guidelines and being sympathetic to the drug company's situation, Blackwell agreed, even though at the expense of considerable extra effort on its part.

Three questions arise:

First, are the FDA guidelines for drug advertising clear as they apply to supplements? These guidelines are applied to journal supplements supported by pharmaceutical companies because of concerns about the necessary separation of commercial and academic interests. Is the purview of the restrictions clearly defined? Should there be a distinction between making such supplements available to the academic community through medical libraries and institutions and distributing them to medical-practitioner subscribers? In cases involving unlicensed use, the FDA is primarily concerned with individual practitioners, not the research or academic community. The FDA considers libraries completely free to request and hold these supplements.

Second, is this an isolated case? No. For example, in recent months, W. B. Saunders has withheld as many as four supplements to Seminars in Oncology from U.S. subscribers because they deal with drugs approved widely in Europe but still under clinical trial in the United States. Either because of its own interpretation of the FDA guidelines or because of the pharmaceutical company's interpretation, Saunders not only withheld distribution from U.S. subscribers but also considered that it could not distribute copies to its own staff members and instead arranged for all copies of the supplements to be shipped to Europe. Anyone requesting information or library copies was told that the FDA guidelines did not allow distribution within the United States. In mid-October, Saunders learned that the FDA did not restrict library access and began to devise a policy for distributing the supplements.

Third, do all parties understand what the guidelines require? On the evidence of these two examples, they do not. Librarians tend not to know that the FDA is unconcerned about their owning these materials and has no authority over libraries and publishers. Further, pharmaceutical companies do not seem to know that they are free to release copies to libraries and other institutional subscribers. Even publishers do not seem aware of the FDA's distinctions, not realizing that the drug 
companies, not the journals, must face FDA scrutiny and sanctions. Medical librarians, medical publishers, and the communities they serve need better information and common approaches to these situations.

When a journal publisher withholds a publication, such as a journal supplement, from a segment of its normal audience, it needs to state explicitly why the publication is being withheld. If a pharmaceutical company has requested that the supplement be restricted because of FDA guidelines on advertising, the publishers should so inform the subscribers. In every such case, the publisher needs to state whether libraries or other institutional subscribers may request their copies and give instructions for obtaining them.

The academic medicine community-including journal editors and publishers and medical librarians-needs to work together to clarify what should happen when commercial support of a publication causes the "good" of regulation of drug advertising to clash with the "good" of the free flow of scientific information. Perhaps the Council of Biology Editors, which has served biomedical publishing well in setting standards for a range of thorny issues involving journals, can take the lead.

Addeane S. Caelleigh

Editor, Academic Medicine

\section{References}

1. TASK FORCE FOR INDUSTRY/CME COLlaboration. Uniform guidelines for commercial support. Chicago, IL: American Medical Association, 1992.

2. Standards for commercial support of continuing medical education. Lake Bluff, IL: Accreditation Council for Continuing Medical Education, 1992.

3. AD HOC COMMITTEE ON MISCONDUCT AND CONFLICT OF INTEREST IN RESEARCH, SUBCOMMTTTEE ON CONFLICT OF INTEREST in Continuing Medical Education. Guidelines for faculty involvement in commercially supported continuing medical education. Acad Med 1992;67: 615-21.

4. Bero L, Galbraith A, RenNie D. The publication of sponsored symposiums in medical journals. New Eng J Med 1992;327:1135-40. 